\title{
A RARE CASE OF SOLITARY FIBROUS TUMOUR OF THE PLUERA IN MANIPUR, INDIA
}

Debobratta Hajong ${ }^{1}$, Lalrinmuani Sailo² ${ }^{2}$ Subrata Kishore Deb Barma ${ }^{3}$, Ksh Kala Singh ${ }^{4}$

\section{HOW TO CITE THIS ARTICLE:}

Debobratta Hajong, Lalrinmuani Sailo, Subrata Kishore Deb Barma, Ksh Kala Singh. "A Rare Case of Solitary Fibrous Tumor of the Pleura in Manipur, India". Journal of Evolution of Medical and Dental Sciences 2014;

Vol. 3, Issue 64, November 24; Page: 14106-14109, DOI: 10.14260/jemds/2014/3888

\begin{abstract}
Solitary fibrous tumor (SFT) is uncommon soft tissue tumors which most frequently occur in the pleura. Most of these tumors project into the pleural cavity in a pedunculated manner from the visceral pleura. Larger tumors in the thoracic cavity may present with dyspnea, chest pain and malaise while smaller tumors are usually asymptomatic. Since its first description in 1931, only 800 cases of such tumors have been reported so far. Here we present a case of a 40 year old housewife with complaints of right sided, vague, dull-aching chest pain for 2 months. Her medical history was unremarkable. Radiologic imaging revealed a large $(16.5 \mathrm{~cm}$ X $10 \mathrm{~cm})$ lobulated mass lesion seen in the right hemi-thorax. Right sided postero-lateral thoracotomy was done and the tumor was excised. Histo-patological examination of the cut section showed benign spindle cell tumor. Immunohistochemistry was positive for CD34. Solitary Fibrous Tumor of the pleura is a rare neoplasm and no such case has been reported so far from Manipur, India. We were successful in detecting; planning and complete surgical removal of the SFT of the pleura in our patient and the patient is under monitoring and follow up to detect any recurrence in near future.
\end{abstract}

KEYWORDS: Pleura, Solitary Fibrous Tumor, CD34, Thoracotomy.

INTRODUCTION: Solitary fibrous tumor (SFT) is uncommon soft tissue tumor which most frequently occurs in the pleura ${ }^{1,2}$ that may be mistaken for mesothelioma. They also have been reported to occur in other sites including the lung, liver, orbit, nasal passages, skin, thyroid and gastrointestinal tract. It originates from the mesenchymal cells of submesothelial tissue of the pleura. ${ }^{3}$ Most of these tumors project into the pleural cavity in a pedunculated manner from the visceral pleura. ${ }^{2,3,4}$ Larger tumors occupying a large space in the thoracic cavity may present with symptoms such as dyspnea, chest pain and malaise while smaller tumors are usually asymptomatic. Since its first description in 1931, only 800 cases of such tumors have been reported so far.5,6 We present here a case of solitary fibrous tumor of the pleura which is not reported yet from the state of Manipur in India.

CASE REPORT: A 40 year old housewife attended the CTVS OPD of RIMS hospital with complaints of right sided, vague, dull-aching chest pain for 2 months. Her medical history was unremarkable. She is a non-smoker with no history of asbestos exposure. A diffuse dull note on percussion and decreased breath sounds on auscultation was noted over the right middle and lower chest. The mediastinum appears to be slightly shifted towards the left side. Patients general and other systemic examination findings were unremarkable. The routine hematological, blood biochemical findings and electrocardiogram were normal.

A roentgenogram showed a homogenous opacity in the right mid and lower zones. Computed tomography (CT) revealed a large $(16.5 \mathrm{~cm}$ X $10 \mathrm{~cm})$ lobulated mass lesion seen in the right hemithorax showing smooth margin with no evidence of calcification or spiculation. The lesion is seen abutting the right cardiac border with mild contralateral shift of the mediastinum. Post contrast study 


\section{CASE REPORT}

shows heterogeneous enhancement. No evidence of mediastinal lymphadenopathy. No evidence of adjacent bony destruction.

The fine needle aspiration cytology was inconclusive. Ultrasound abdomen showed no other abnormality except right sided minimal pleural effusion. Right sided posterolateral thoracotomy was done through the fifth intercostal space and the tumor was excised. Intra-operatively a well encapsulated circumscribed gigantic tumor mass measuring $14 \mathrm{X} 13 \mathrm{X} 10 \mathrm{~cm}$ with greyish white glistening smooth surface with two smaller, well encapsulated, lobulated masses $(5 \times 4 X 3 \mathrm{~cm}$ and $3 \mathrm{X} 3 \mathrm{X} 2 \mathrm{~cm}$ ) connected to the bigger tumor mass in the proximal part, all of which arises from a common peduncle from the visceral surface of the pleura was noted. Cut surface showed a well encapsulated lobulated grey white tumor without any areas of necrosis. Histopatological examination (HPE) of the cut section showed benign spindle cell tumor cells arranged in short intersecting fascicles, in a pericystic distribution around ramifying blood vessels with occasional mitotic figure $(<1 / 100 \mathrm{hpf})$.

Immunohistochemistry was positive for CD34. Post-operatively patient recovered well and tumor removal was confirmed with post-operative CECET thorax.

DISCUSSION: At present the SFTs are believed to arise from the submesothelial tissue of the pleura, mostly the visceral pleura (80\%). Commonly they are pedunculated tumor although sessile and inverted tumors invading lung parenchyma are reported in the literature. SFTs represent less than $5 \%$ of pleural tumours, ${ }^{7}$ the commoner being diffuse pleural tumor or mesothelioma. $80 \%$ of SFTs are bening. ${ }^{6}$ The presentation depends on the size of the tumor with larger tumors giving rise to symptoms due to extrinsic compression of the lung parenchyma as cough, dyspnea and chest pain. More than $33 \%$ of the patients with symptoms present with Hypertrophic Pulmonary Osteoarthropathy. ${ }^{8}$ Doege-Potter Syndrome, a paraneoplastic phenomenon may present with tumor with associated hypoglycemia due to insulin like growth factor. ${ }^{9}$ These tumors usually occur in the fifth or sixth decade of life and there is no sex predeliction.4,10 No association is seen with asbestos, tobacco, any environmental agent or any apparent genetic predisposition.

Chest radiography is the initial diagnostic test even though it is not specific. CT scan helps in delineating the size and location of the tumor clearly and helps in surgical planning. Transthoracic FNAC can be used as a definitive diagnostic modality pre-operatively although many authors do not recommend it. Scarsbrook and colleagues ${ }^{11}$ has mentioned about the tumor seedlings on the biopsy tract after USG guided transthoracic biopsy and recommended biopsy to be done only in case surgical intervention is contraindicated and in the case where the FNAC result will significantly aid in alternative disease management. ${ }^{11}$

The SFTs can be differentiated from mesotheliomas and other sarcomas by the presence of specific bio-markers which are detectable by immune-histochemical analysis. SFTs are CD 34 positive while most of the other pulmonary tumors are CD 34 negative. SFTs are vimentin positive and cytokeratin negative while mesotheliomas are vimentin negative and cytokeratin positive. SFTs are strongly positive for bcl-2 and its presence can help diagnosing SFTs in CD 34 negative patients. SFTs are CD99 positive and S-100 negative. ${ }^{4}$ The gold standard for final diagnosis of SFT remains the surgical excision and HPE, even though the imaging techniques are still the first fundamental tool for initial diagnosis based on the morphological and functional features of the tumor. HPE usually shows cellular areas with intermittent hyalinized or necrotic areas, while microscopy shows both fibroblasts and mesothelial cells. ${ }^{8}$ 
Complete surgical resection is the preferred therapy for both the benign and malignant SFTs. ${ }^{6}$ Wedge resection of the pedunculated tumor usually suffices while for sessile lesions a clear margin involving resection of a larger amount of lung parenchymal tissue is excised to prevent local tumor recurrence. ${ }^{6}$ Benign, sessile SFTs, shows $8 \%$ chance of recurrence as against $2 \%$ in benign pedunculated group as compared with $63 \%$ with malignant sessile and $14 \%$ with malignant pedunculated group even after complete resection. ${ }^{4}$

Malignant histology, parietal pleural origin and lower expression of progesterone receptors are some factors associated with tumor recurrence. ${ }^{12}$ One review of literature shows a SFT with four times recurrence within 10yrs period ending finally with a malignant transformation. ${ }^{13}$ The recovery rate is estimated at $88 \%-92 \%$ for all patients with solitary fibrous pleural tumours 6 following successful complete surgical resection even though careful follow-up is still necessary. The median survival for all types of SFTs has been reported to be 24 years. $^{7}$

CONCLUSION: Solitary Fibrous Tumor of the pleura is a rare neoplasm and no such case has been reported so far from the State of Manipur, India. We were successful in detecting, planning and complete surgical removal of the SFT of the pleura in our patient. At present the patient is under monitoring and follow-up every 3-6 months to detect any recurrence in near future. Fortunately, the SFTs are benign $80 \%$ of time rendering them treatable with careful, complete surgical resection. Although malignant varieties of Solitary fibrous tumor of the pleura has got higher recurrence rate during follow up early detection of recurrence and repeat surgical intervention with careful postoperative surveillance may still permit long time survivals in as many as $70 \%$ of these patients.

\section{REFERENCES:}

1. Goodland JR, Fletcher CDM. Solitary fibrous tumour arising at unusual sites: analysis of a series. Histopathology 1991; 19; 515-22.

2. Sakurai H, Tanaka W, Kaji M, Yamazaki K, Suemasu K. intrapulmonary localized fibrous tumour of the lung: A very unusual presentation. Ann Thorac Surg 2008: 86: 1360-2.

3. Magdeleinat P, Alifano M, Petino A, Le Rochais JP, Dulmet E, Galateau F, Icard P, Regnard JF. Solitary fibrous tumours of the pleura: clinical characteristics, surgical treatment and outcome. Eur J Cardiothoracic Surg 2002; 21: 1087-93.

4. De Perrot M, Fischer S, Brundler MA, Sekine Y, Keshavjee S. Solitary fibrous tumour of the pleura. Ann Thorac Surg 2002; 74: 285-93.

5. Klemperer P, Robin CB. Primary neoplasms of the pleura. Arch Pathol. 1931; 11: 386-411.

6. Robinson LA. Solitary fibrous tumours of the pleura [review]. Cancer Control. 2006; 13: 264269.

7. Harrison-Phipps KM, Nichols FC, Schleck CD et al. Solitary fibrous tumours of the pleura: result of surgical treatment and long term prognosis. J Thorac Cardiovasc Surg 2009; 138: 19-25.

8. Briselli M, Mark EJ, Dickerson GR. Solitary fibrous tumours of the pleura: eight new cases and review of 360 cases in the literature. Cancer. 1981; 47: 2678-89.

9. Balduyck B, Lauwers P, Govaert K, Hendriks J, De Maeseneer M, Van Schil P. Solitary fibrous tumour of the pleura with associated hypoglycemia: Doege-Potter syndrome: a case report. J Thorac Oncol.2006; 1: 588-90. 


\section{CASE REPORT}

10. Shields TW, Yeldani AV. Localised fibrous tumour of the pleura. In: Shields TW, Locicero J, Ponn RB, Rusch VW, editors General Thoracic Surgery; $6^{\text {th }}$ edition. Philadelphia: Lippincott Williams and Wilkins; 2005.

11. Scarsbrook AF, Evans AL, Slade M, Gleeson FV. Recurrent Solitary fibrous tumour of the pleura due to tumour seedling following ultrasound guided transthoracic biopsy. Clin Radiol. 2005; 60: 130-32.

12. Carretta A, Bandiera A, Melloni G, Ciriaco P, Arrigoni G, Rizzo N, et al. Solitary fibrous tumours of the pleura; immunohistochemical analysis and evaluation of prognostic factors after surgical treatment. J Surg Oncol. 2006, 94: 40-44.

13. Kanthan R, Torkian B. Recurrent solitary fibrous tumour of the pleura with malignant transformation. Arch Pathol Lab Med. 2004; 128: 460-62.

\section{AUTHORS:}

1. Debobratta Hajong

2. Lalrinmuani Sailo

3. Subrata Kishore Deb Barma

4. Ksh Kala Singh

\section{PARTICULARS OF CONTRIBUTORS:}

1. PGT, Department of Surgery, RIMS, Imphal, Manipur.

2. PGT, Department of Surgery, RIMS, Imphal, Manipur.

3. PGT, Department of Surgery, RIMS, Imphal, Manipur.

4. Professor \& HOD, Department of CTVS, Imphal, Manipur.

\section{NAME ADDRESS EMAIL ID OF THE CORRESPONDING AUTHOR:}

Dr. Lalrinmuani Sailo,

PG Ladies Hostel 1,

Room 64, RIMS,

Imphal-795004,

Manipur.

Email: rynsailo@gmail.com

Date of Submission: 09/11/2014.

Date of Peer Review: 10/11/2014.

Date of Acceptance: 18/11/2014.

Date of Publishing: 24/11/2014. 